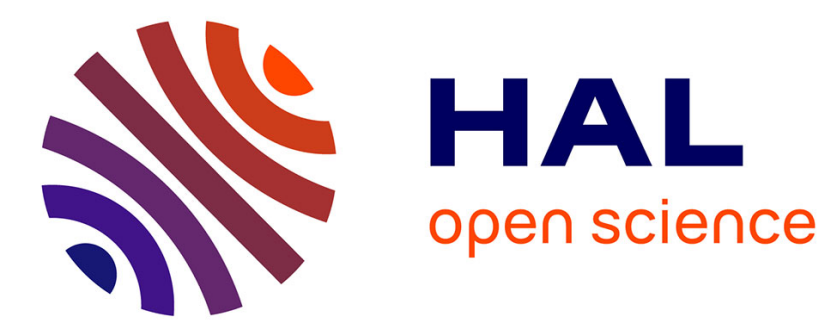

\title{
On the arc transition mechanism in nanosecond air discharges
}

Nicolas Minesi, Sergey Stepanyan, Pierre Mariotto, Gabi-Daniel Stancu, Christophe O Laux

\section{- To cite this version:}

Nicolas Minesi, Sergey Stepanyan, Pierre Mariotto, Gabi-Daniel Stancu, Christophe O Laux. On the arc transition mechanism in nanosecond air discharges. AIAA Scitech 2019 Forum, Jan 2019, San Diego, United States. 10.2514/6.2019-0463 . hal-01990137

\section{HAL Id: hal-01990137 https://hal.science/hal-01990137}

Submitted on 11 Feb 2019

HAL is a multi-disciplinary open access archive for the deposit and dissemination of scientific research documents, whether they are published or not. The documents may come from teaching and research institutions in France or abroad, or from public or private research centers.
L'archive ouverte pluridisciplinaire HAL, est destinée au dépôt et à la diffusion de documents scientifiques de niveau recherche, publiés ou non, émanant des établissements d'enseignement et de recherche français ou étrangers, des laboratoires publics ou privés. 
See discussions, stats, and author profiles for this publication at: https://www.researchgate.net/publication/330197677

\section{On the arc transition mechanism in nanosecond air discharges}

Conference Paper · January 2019

DOI: 10.2514/6.2019-0463

CITATIONS

5 authors, including:

Dicolas Minesi

282. CentraleSupélec

3 PUBLICATIONS 1 CITATION

SEE PROFILE

Christophe O Laux

CentraleSupélec

219 PUBLICATIONS 3,455 CITATIONS

SEE PROFILE

Some of the authors of this publication are also working on these related projects:

Project Ablation-Flowfield Coupling : Carbon Monoxide Formation in a High Temperature Boundary Layer View project

CO2 Conversion with Non-Equilibrium Discharges View project
READS

17

Sergey Stepanyan

CentraleSupélec

21 PUBLICATIONS 111 CitATIONS

SEE PROFILE 


\title{
On the arc transition mechanism in nanosecond air discharges
}

\author{
N. Minesi, S. Stepanyan, P. Mariotto, G. D. Stancu and C. O. Laux \\ EM2C Laboratory, CNRS UPR288, CentraleSupélec, Université Paris Saclay, 3 rue Joliot-Curie 91190 Gif-sur- \\ Yvette France
}

\begin{abstract}
Nanosecond repetitively pulsed discharges can be classified into three types: the corona, the glow and the spark. The experimental parameters triggering the transition between these regimes are well understood. Corona and glow are non-equilibrium plasmas. The spark plasma can be in non-equilibrium or in equilibrium, the equilibrium regime being called hereafter the arc regime. The transition from the non-equilibrium spark to the arc regime for nanosecond discharges is not entirely understood. This is accompanied by a sharp rise of the gas temperature and electron number density that cannot be explained by conventional mechanisms. In this paper, spatially and temporally resolved emission was performed before, during and after the arc transition, which was found on a time scale below $1 \mathrm{~ns}$. We compare the measurements of the electron number density and the electronic temperature before and after the transition. According to the present results, the electron number density rises from typical values of $10^{15}$ to $10^{19} \mathrm{~cm}^{-3}$ and the gas temperature increases from $1,000 \mathrm{~K}$ to $40,000 \mathrm{~K}$. The presented measurements are intended to help explain the transition mechanism.
\end{abstract}

\section{Introduction}

Corona, glow and spark discharges have been investigated for various conditions [1]-[4] and have been applied to combustion [5], [6], nanomaterial synthesis [7], [8] and flow control [9]-[11]. Typical parameters of these discharges are presented in Table 1. The corona and the glow discharges are non-thermal plasmas in non-equilibrium and the electrical energy deposited in the gas is spent mainly on electronic and vibrational excitation of $\mathrm{N}_{2}$. A description of the glow regime can be found in [4]. In the spark regime a quick transfer of the electrical energy into the thermal energy occurs, but is still out of equilibrium plasma [1]. The transition between these non-equilibrium regimes of nanosecond discharges were investigated by Pai et al. [3]. It should be mentioned that different research groups use different terminologies defining the spark plasma, and that in the literature the spark is often referred as an equilibrium plasma. In the present article, in order to distinguish non-equilibrium and equilibrium sparks we will use the following terminology: the equilibrium spark will be called "arc", while the non-equilibrium spark will be simply called "spark" (to be consistent with previous publications [1]-[4]).

One can see from Table 1 that the transition to the arc increases the electron number density and the gas temperature. It has been demonstrated recently [12] that this transition occurs for nanosecond plasmas in less than $5 \mathrm{~ns}$. We note that spectra before the transition are dominated by molecular emission (in air, the second positive system of $\mathrm{N}_{2}$ ), while the spectra after the transition are dominated by a broadband continuum emission and ion lines of $\mathrm{N}^{+}$. It was mentioned in [12] that emission of $\mathrm{N}$ lines can be seen later in the afterglow. A similar transition (called "streamer-to-filament") accompanied by a switch from molecular to ionic/atomic emission was observed in [13]. In both cases [12], [13] the electron number density measured by Stark broadening of $\mathrm{N}^{+}$or $\mathrm{H} \alpha$ was close to full ionization (approximately $10^{19}$ $\mathrm{cm}^{-3}$ ). The mechanism of this transition is not understood yet. Particularly, the mechanism of ultra-fast gas heating in air [2], [14], [15] cannot explain the sharp rise of temperature after transition to the arc.

In this work spatially and temporally resolved Optical Emission Spectroscopy (OES) measurements were performed, the absolute electron number density, the electronic temperature and their distributions were obtained from Stark broadening of $\mathrm{N}^{+}$lines and Boltzmann distribution of the $\mathrm{N}^{+}, \mathrm{O}^{+}$electronic states, respectively.

American Institute of Aeronautics and Astronautics 
Table 1 Typical parameters of corona, glow [4], spark [1], [2] and arc nanosecond discharges at ambient conditions ( $p=1$ bar, $\mathbf{T}=300 \mathrm{~K}$ ). The deposited electrical energy is valid if the extension of the plasma is in the mm scale.

\begin{tabular}{|c|c|c|c|c|}
\hline Parameter & Corona & Glow & Spark & Arc \\
\hline State & Non-equilibrium & Non-equilibrium & Non-equilibrium & Equilibrium \\
\hline $\begin{array}{c}\text { Total Deposited Electrical } \\
\text { Energy }\end{array}$ & $\sim 1-10 \mu \mathrm{J}$ & $\sim 10 \mu \mathrm{J}$ & $\sim 1 \mathrm{~mJ}$ & $\sim 1 \mathrm{~mJ}$ \\
\hline Dominant Emission & Molecular $\left(\mathrm{N}_{2}\right)$ & Molecular $\left(\mathrm{N}_{2}\right)$ & Molecular $\left(\mathrm{N}_{2}\right)$ and Atomic $(\mathrm{O})$ & Atomic $(\mathrm{N}, \mathrm{O})$ and Ionic $(\mathrm{N}+, \mathrm{O}+)$ \\
\hline Electron Number Density & $<10^{13} \mathrm{~cm}^{-3}$ & $10^{13} \mathrm{~cm}^{-3}$ & $10^{15} \mathrm{~cm}^{-3}$ & $10^{19} \mathrm{~cm}^{-3}$ \\
\hline Gas Temperature Increase & $\sim 0 \mathrm{~K}$ & $\sim 200 \mathrm{~K}$ & $\sim 1000-2000 \mathrm{~K}$ & $\sim 40,000 \mathrm{~K}$ \\
\hline
\end{tabular}

\section{Experimental Setup}

The experiments presented here were performed for nanosecond discharges initiated by high voltage pulses between two pin tungsten electrodes in ambient air. The distance between the electrodes was 1,3 and $6 \mathrm{~mm}$. The curvature radius of electrodes was approximately $200 \mu \mathrm{m}$. The nanosecond discharge was generated by an FID FPG 30$100 \mathrm{MC} 4 \mathrm{~K} 10$-ns HV pulse generator, with pulse amplitudes up to $30 \mathrm{kV}$ and pulse repetition frequencies up to 100 $\mathrm{kHz}$. A scheme of the experimental setup can be found in Fig. 1. For the interelectrode gaps of 1 and $6 \mathrm{~mm}$ (referred further as 1- and 6-mm case), positive and negative voltage polarity were applied to the anode-cathode system, with a maximum potential difference of $30 \mathrm{kV}$. In the $3-\mathrm{mm}$ electrode gap case, the electrical setup was changed to a cathodeground configuration with the typical waveform shown in Fig. 2. Discharges were initiated at a maximum frequency of $50 \mathrm{~Hz}$ to avoid interaction between two consecutive pulses. The electrical characteristics of the discharge were monitored by high voltage (LeCroy PPE20kV) and current probes (Pearson 6585) connected to the electrodes system and the oscilloscope (Lecroy HDO 6104). The procedure for energy measurements is described in [16], [17]. The length of cables connecting the electrodes to the generator was long enough to distinguish the pulses emitted by the pulser and their reflections in the electrical circuit.

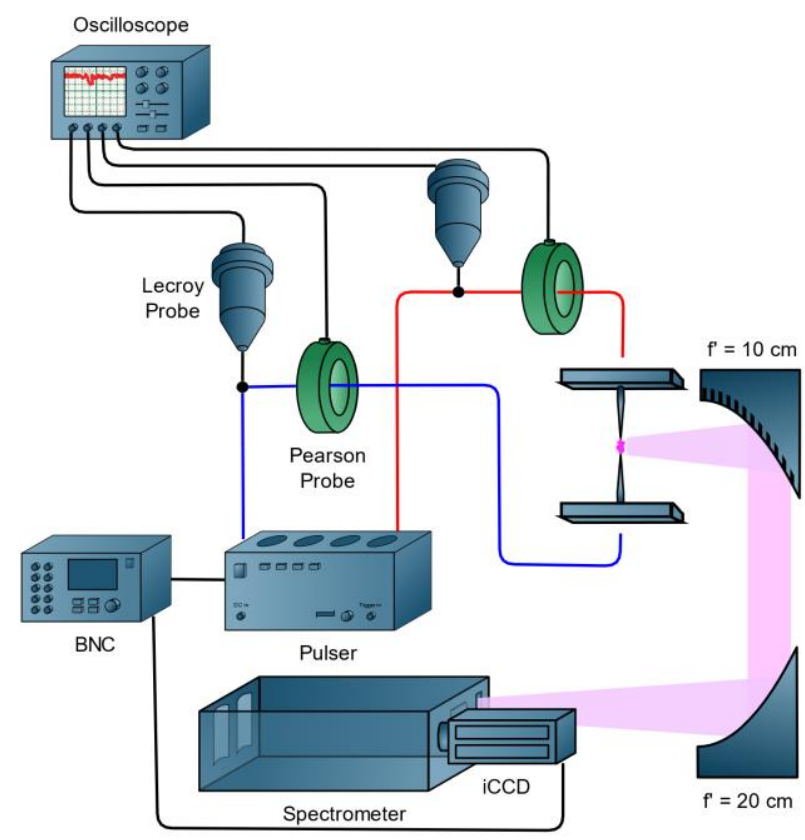

Fig. 1 Experimental setup for electrical measurements and OES. This configuration was used for interelectrode gaps of 1 and $6 \mathrm{~mm}$. In the 3-mm case the anode was connected to the ground instead of the positive polarity. 


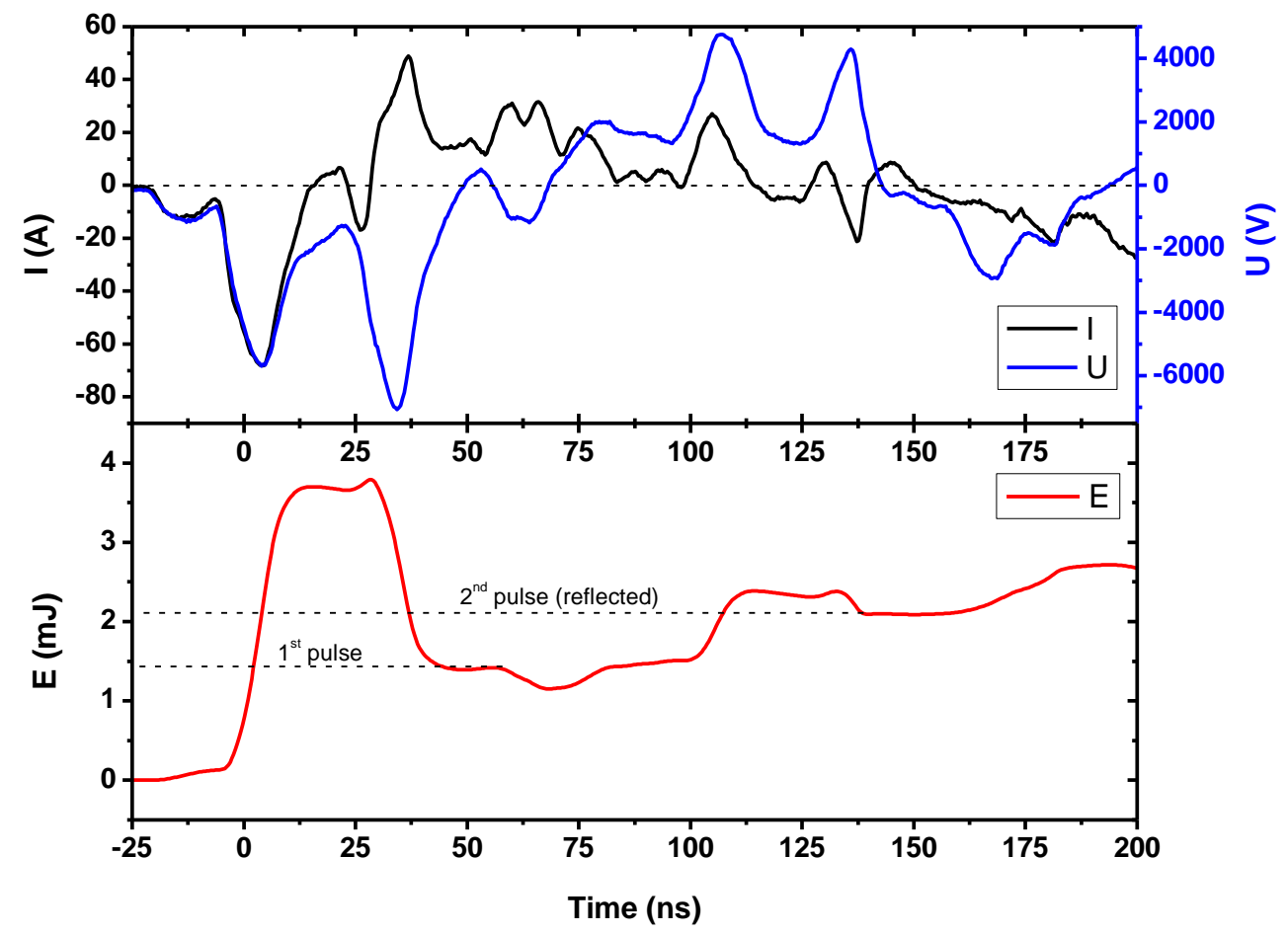

Fig. 2 (top figure) Recorded voltage and current applied in the 3-mm configuration, in ambient air. The width of the pulse is approximately $10 \mathrm{~ns}$. The incident voltage is $-5 \mathrm{kV}$ (corresponding to $-10 \mathrm{kV}$ at the pin-to-pin gap when reflected on its infinite impedance) and incident current 70 A. One can see at $t=0$ ns the pulse sent by the pulser and at $t=30 \mathrm{~ns}$ its reflection from the plasma. At $t=100 \mathrm{~ns}$, a new pulse arises due to another reflection of the pulse on the generator. (bottom figure) Calculated energy calculated from the oscillograms of $U$ and $I$. The energy deposited by the first pulse is approximately $1.5 \mathrm{~mJ}$. The second pulse deposits $0.6 \mathrm{~mJ}$.

OES measurements were made by placing the discharge at the focal point of an off-axis parabolic mirror $(\mathrm{f}=10 \mathrm{~cm})$; the collimated light was then focused by a second parabolic mirror $(\mathrm{f}=20 \mathrm{~cm}$ ) on the spectrometer (Acton $500 \mathrm{i}) \mathrm{slit}$. An ICCD camera PI-MAX4 was used to record the spectra, using 300 or 600 grooves $/ \mathrm{mm}$ gratings. The reference time $(\mathrm{t}=0 \mathrm{~ns})$ was set to the first acquired signal with the minimal gate $(0.42 \mathrm{~ns})$. A HeNe laser was used to determine the slit function of the spectrometer.

Contribution of the various broadening widths of ion lines $\left(\mathrm{N}^{+}, \mathrm{O}^{+}\right)$, namely natural broadening, pressure broadening (resonant, Van der Waals) and Doppler broadening were estimated based on [18]. It was found that the Stark effect is the main broadening mechanisms. Reference tables [19], [20] provide factors for converting the fullwidth at half maximum (FWHM) of atomic/ionic lines to electron number density. 


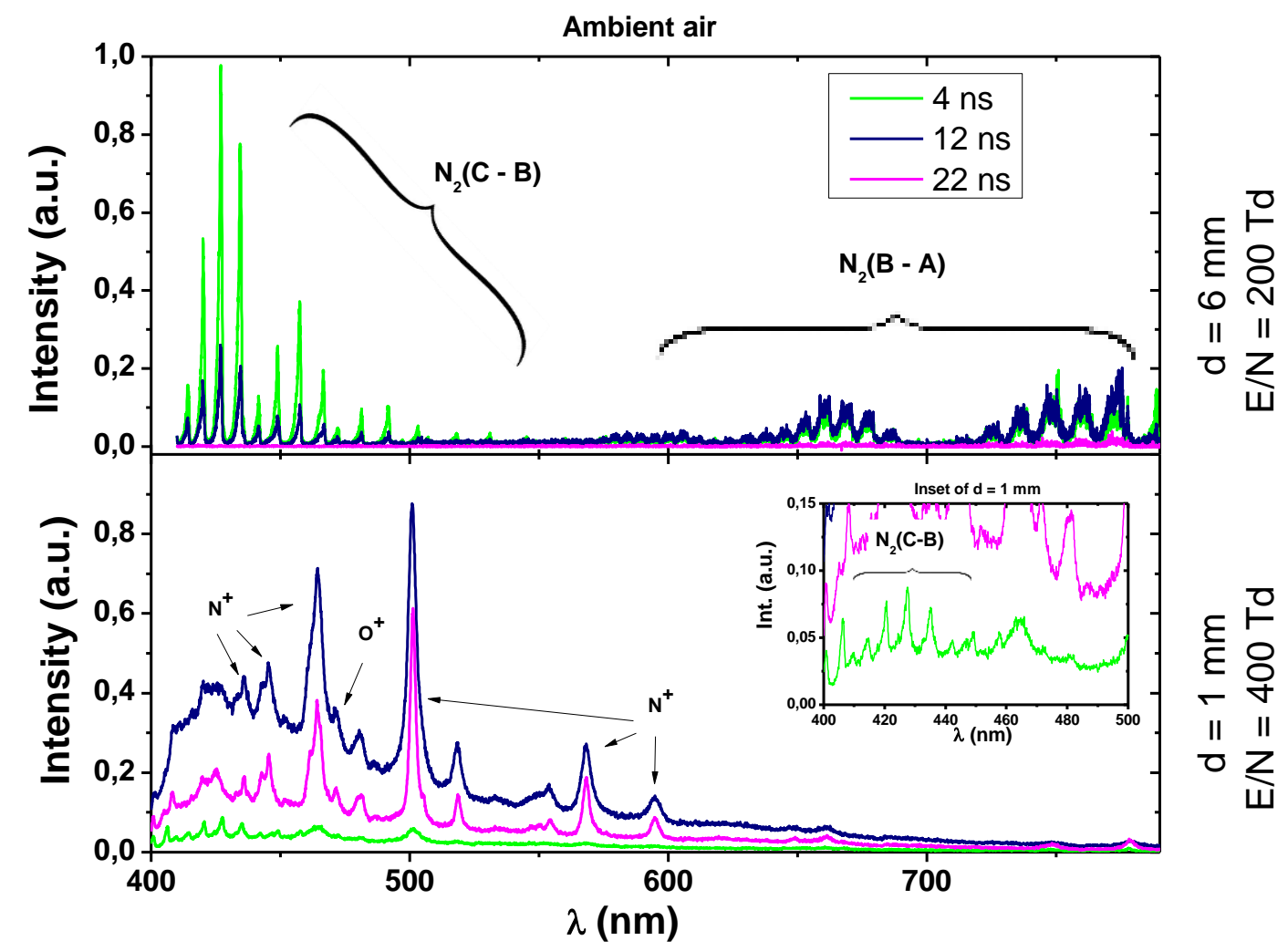

Fig. 3 Spectra obtained during and after a 10-ns pulse in ambient air. The breakdown voltage of the pulse was $11 \mathrm{kV}$ for the 1-mm gap, and $30 \mathrm{kV}$ for the 6-mm gap, resulting respectively in a reduced electric field of 440 and $200 \mathrm{Td}$ at breakdown. We display here the spectra at $t=4,12$ and $22 \mathrm{~ns}$. The intensity scales of the two spectra are not the same. Case $\mathrm{d}=6 \mathrm{~mm}$ (top): we identified the emission of the first and second positive systems of nitrogen. Case $\mathrm{d}=1 \mathrm{~mm}$ (bottom): ionic lines of nitrogen and oxygen were identified. No Tungsten lines (electrode material) were seen in this range.

\section{Experimental Results}

Using the experimental setup described above, we recorded the emission spectra of a 1-mm and 6-mm discharge between 400 and $800 \mathrm{~nm}$. The second order emission was cut by a high-pass filter (Melles Griot 03FCG 055, cut-off below $400 \mathrm{~nm}$ ). The electrodes were both polarized by a positive and a negative pulse (i.e. none of them was grounded). Fig. 3 shows the emission spectra of the discharge initiated in ambient air ( $\mathrm{P}=1 \mathrm{~atm})$ for 1 and $6 \mathrm{~mm}$ interelectrode distances. For each configuration we plot 3 spectra: (a) before the transition ( $4 \mathrm{~ns}$ ), (b) after the transition $(12 \mathrm{~ns})$ and (c) in the post discharge (22 ns). Spectra were obtained with an ICCD camera gate of $2 \mathrm{~ns}$. The spectrum presented at the top of Fig. 3 was obtained for the 6-mm interelectrode gap and an applied voltage of $30 \mathrm{kV}$ $(\mathrm{E} / \mathrm{N}=200 \mathrm{Td})$. In this case the spark-arc transition does not occur. Therefore the spectra during and after the pulse are mostly due to molecular nitrogen as shown in numerous references before [1], [2]. The intensity of the molecular emission is maximal during the pulse. After the pulse, when no more energy is supplied to the plasma, the intensity of the discharge quickly decreases and, at $\mathrm{t}=22 \mathrm{~ns}$, no more emission is visible with the camera settings we used. Then, we moved the pins closer, from 6- to 1-mm gap. The same pulse was applied to initiate the discharge but breakdown occurred at $11 \mathrm{kV}$ (i.e. before the maximum voltage was reached). The total emission intensity increases while the electric energy is introduced to the gas, reaches a maximum at around 10-14 ns and then slowly decays after the end of the pulse. At $\mathrm{t}=4 \mathrm{~ns}$, the second positive system is visible, but already as intense as the broad continuum. Then follows the transition to the arc $(t=12 \mathrm{~ns})$ accompanied by a dramatic increase of emission in the visible spectrum. The strongest lines are from to the excited states of $\mathrm{N}^{+}$and $\mathrm{O}^{+}$states. The main contribution to the overall 


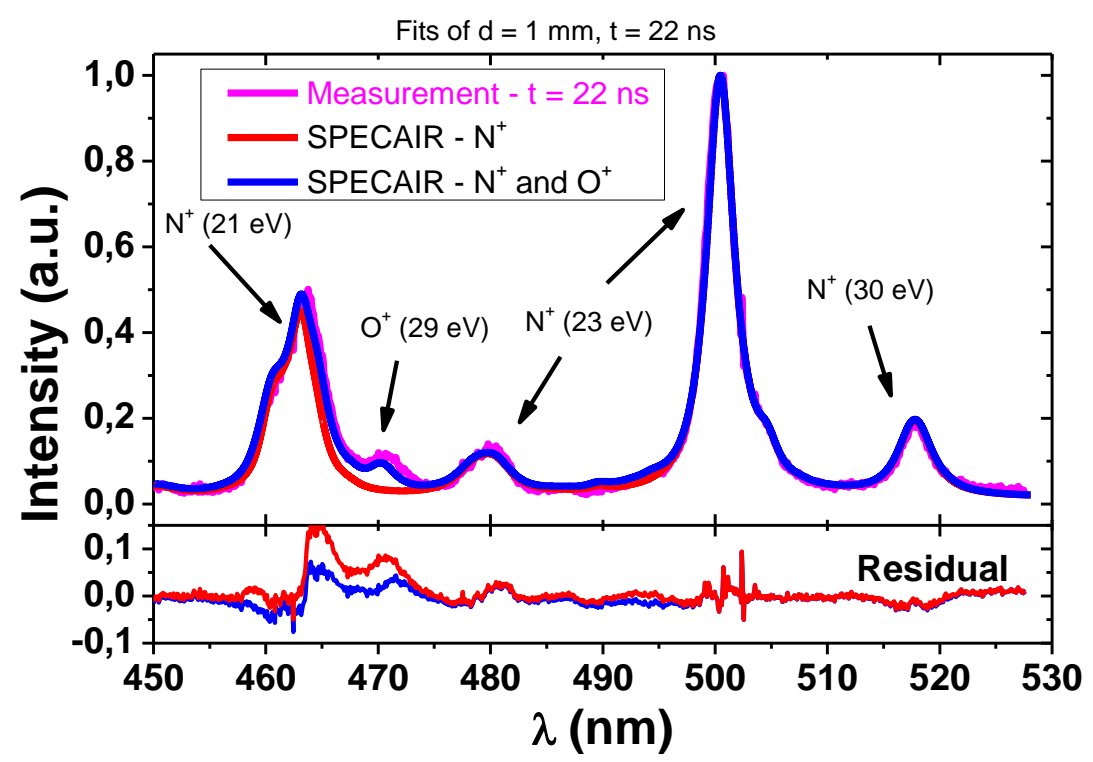

Fig. 4 - We fitted the spectrum of Fig. 3 at $t=22 \mathrm{ns,} \mathrm{after} \mathrm{removing} \mathrm{the} \mathrm{continuum} \mathrm{emission} \mathrm{by} \mathrm{a} \mathrm{linear} \mathrm{approximation.} \mathrm{We}$ simulated the emission of $\mathrm{N}^{+}$(red curve) broadened by electron number density and the slit function. The emission of $\mathrm{O}^{+}$ was then added assuming its temperature to be equal to those of $\mathrm{N}^{+}$. The addition of $\mathrm{O}^{+}$in the spectrum significantly decreased the residual shown in the lower part of the figure. Residual is shown and a local maximum of $10 \%$ error is obtained. We believe this error may be cause by the Stark shift which is not yet implemented in SPECAIR for these lines.

emission is due to the broadband continuum emission. At $\mathrm{t}=22 \mathrm{~ns}$, emission can still be collected by the camera and the total emission is still of the order of magnitude of the emission at $t=12 \mathrm{~ns}$. In [21] it is shown that an external field contributes to the Stark broadening. In consequences the electron density cannot be directly deduced from the ionic lines width when an external field is applied. At $\mathrm{t}=22 \mathrm{~ns}$, no voltage is applied in the interelectrode gap and the electron number density can be deduced from the width of the emission lines. Subtracting the continuum, we fitted in Fig. 4 the emission of $\mathrm{N}^{+}$and $\mathrm{O}^{+}$at $\mathrm{t}=22 \mathrm{~ns}$, using SPECAIR code [22]. We also choose to analyze this spectrum due to its high value of signal-to-continuum ratio. The broadening of the lines was simulated using a Lorentzian profile convolved with the slit function. We obtained $\mathrm{n}_{\mathrm{e}}=1.2( \pm 0.2) \times 10^{19} \mathrm{~cm}^{-3}$ and using the relative intensity of $\mathrm{N}^{+}$ electronic levels (most intense levels of $\mathrm{N}^{+}: 20.94,21.15,23.25$ and $30.12 \mathrm{eV}$; most intense levels of $\mathrm{O}^{+}: 31.15$ and $28.88 \mathrm{eV}$ ), we fitted an electronic temperature of $\mathrm{T}_{\mathrm{N}^{+}}=39,000( \pm 4000) \mathrm{K}$. These results are close to those obtained in Ref. [12]. Assuming $\mathrm{T}_{\mathrm{N}^{+}}=\mathrm{T}_{\mathrm{O}}$, we obtained the best fit of Fig. 4 at a ratio of densities $\left[\mathrm{N}^{+}\right] /\left[\mathrm{O}^{+}\right]=4.1( \pm 1)$, close to the Local Thermal Equilibrium (LTE) ratio of 3.6. The uncertainty on the electron number density was estimated by comparing the measured spectra with over- and sub-broadened spectra. The error on the electronic temperature was calculated using a method of uncertainty propagation, assuming a maximum uncertainty of $10 \%$ on the relative intensities and the uncertainties on Einstein coefficients listed by NIST [23]. Between $t=0$ and $t=20 \mathrm{~ns}$, no hydrogen lines were observed in the spatially averaged spectra, even though the discharge was ignited in ambient (humid) air. This can be explained by the high electron number density. At $n_{e}=10^{19} \mathrm{~cm}^{-3}$, the width of the Ha line is more than $25 \mathrm{~nm}$ [24], [25] and its emission is integrated in the continuum emission. The same effect, but more pronounced, is seen on $\mathrm{H} \beta$.

The mechanism of the arc transition remains unknown. An important question to be answered is whether the transition occurs as a wave propagating in the interelectrode gap or is starts homogeneously at the same time in the interelectrode gap. For this purpose spatially resolved measurements were done. In Fig. 5 the evolution of the discharge intensity with a $0.5 \mathrm{~ns}$-gate is showed. The distance between the electrodes was increased to $3 \mathrm{~mm}$ in order to observe the spatial evolution of the transition (not visible in the $1 \mathrm{~mm}$ gap). As already described in the setup section, the electrical arrangement was changed to a cathode-ground configuration. The central wavelength of the grating was set to $0 \mathrm{~nm}$, 

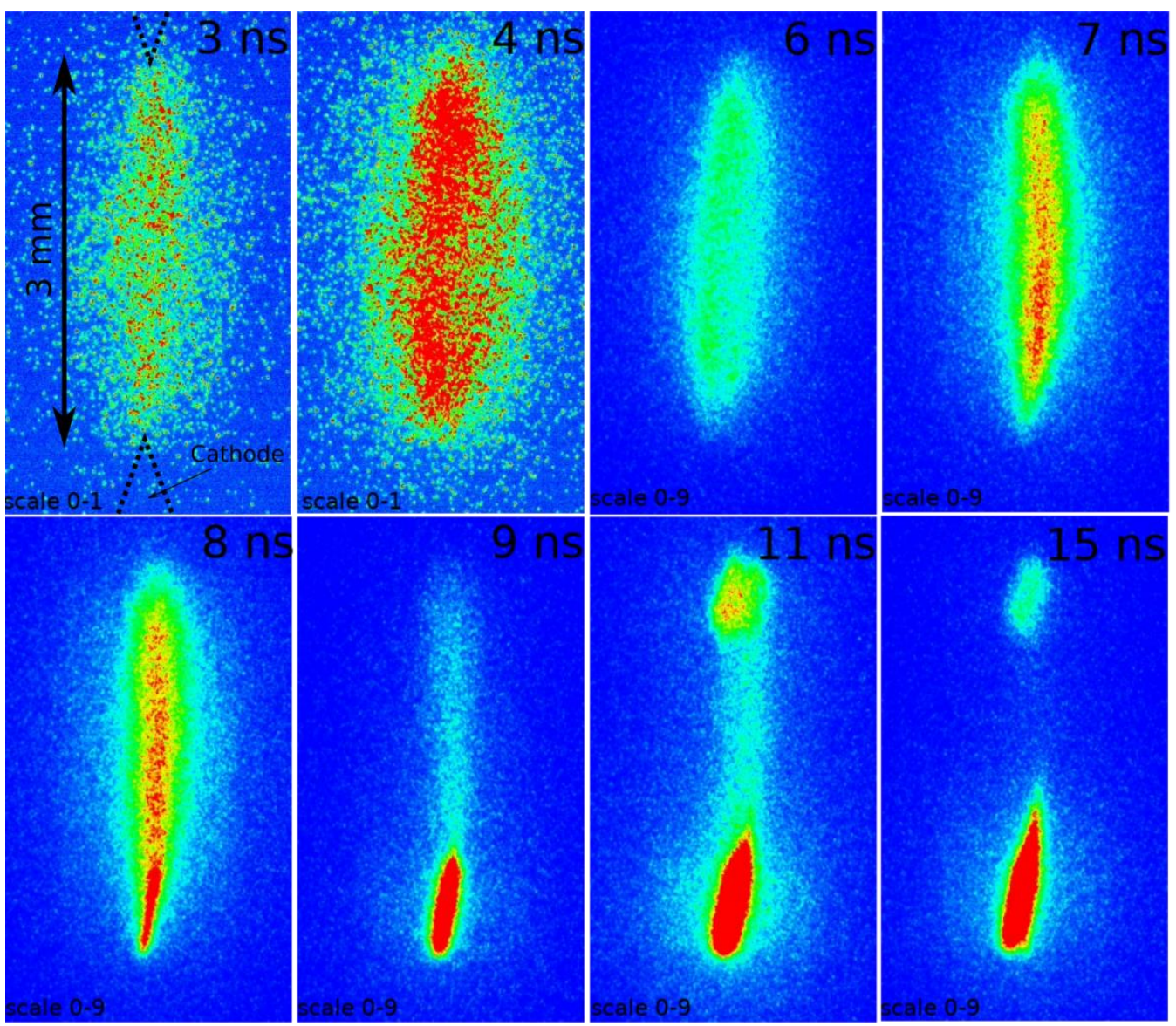

Fig. 5 Spatially resolved images of a nanosecond spark. Electrodes are represented on the first image, cathode at the bottom. The time on top right corner corresponds to the delay of the acquisition with first detectable emission. The interelectrode gap was $3 \mathrm{~mm}$ and the pulse $10 \mathrm{~ns}$ long. The camera gate was $0.5 \mathrm{~ns}$ and exposition on the CCD was not averaged. The typical electrical waveforms are showed in Fig. 2. The scale of intensity presented in the bottom left corner of each image (blue to red) is not the same for all pictures, in order to make the first stage $(0-5 \mathrm{~ns})$ visible. The transition occurs between $t=7 \mathrm{~ns}$ and $t=9 \mathrm{~ns}$ when an intense emission from the cathode becomes visible.

allowing to record the total emission of the discharge. These pictures were obtained by phase-locked acquisition, assuming the reproducibility of the discharge. The time jitter of discharge breakdown (i.e. first registered emission) was found to be below one nanosecond. However, the arc transition time had 2-ns uncertainty. This jitter has already been observed before [26]. Fig. 5 presents typical discharge images before and after transition to the arc. They were selected taking into account the jitter. For the sake of clarity, only a set of representative delays have been displayed $(\mathrm{t}=3,4,6,7,8,9,11,15 \mathrm{~ns})$. In the first two acquisitions $(\mathrm{t}=3-4 \mathrm{~ns})$ the emission is homogeneous along the plasma channel. The thickness of the discharge at $\mathrm{t}=3-6 \mathrm{~ns}$ is about $0.8 \mathrm{~mm}$. At $\mathrm{t}=7 \mathrm{~ns}$, the discharge thickness starts to decrease. At $\mathrm{t}=8 \mathrm{~ns}$, a bright filament appears at the cathode and grows toward the middle of the gap. At $\mathrm{t}=11 \mathrm{~ns}$ another, less intense, filament is formed at the anode. The total thickness of these filaments is approximately $0.2 \mathrm{~mm}$. This change of discharge morphology is often called "constriction" [13], [27] even though it does not correspond to an inward motion of particles. Looking at the images obtained at $\mathrm{t}=11 \mathrm{~ns}$ and $\mathrm{t}=15 \mathrm{~ns}$, one can see an intensity fluctuation of the anode filament from shot to shot.

Fig. 6 presents the spectra corresponding to the images in Fig. 5. The slit was aligned and parallel with the electrode axis. The second order of emission was removed using an optical high-pass filter $(\lambda=400 \mathrm{~nm})$. It should be noted that these spectra are averaged on 1000 acquisitions. Transition jitter mentioned above should be taken into account for an interpretation of the averaged spectra obtained from 7 to $9 \mathrm{~ns}$. For $\mathrm{t}<7 \mathrm{~ns}$, the main contribution to the spectra is due 
to the second positive system of $\mathrm{N}_{2}$ and is homogenous along the interelectrode gap. After transition to the arc, the spectra are dominated by continuum, and ionic emission of nitrogen and oxygen atoms. The emission of $\mathrm{N}^{+}$can be identified by broad (>1 nm) lines at 480,500 and $518 \mathrm{~nm}$. The dynamics of emission is identical to what was described in Fig. 5. In Fig. 5,6, we observe a propagation phenomenon starting from the cathode to about $40 \%$ of the gap length. The characteristic speed of this wave is about $10 \mu \mathrm{m} / \mathrm{ns}$. This observation shows that the arc transition starts in our conditions at the cathode and propagates toward the gap center, increasing emission intensity of ions and thus the gas temperature and the electron number density. It should be noted that there is also a spot of high intensity at the anode.

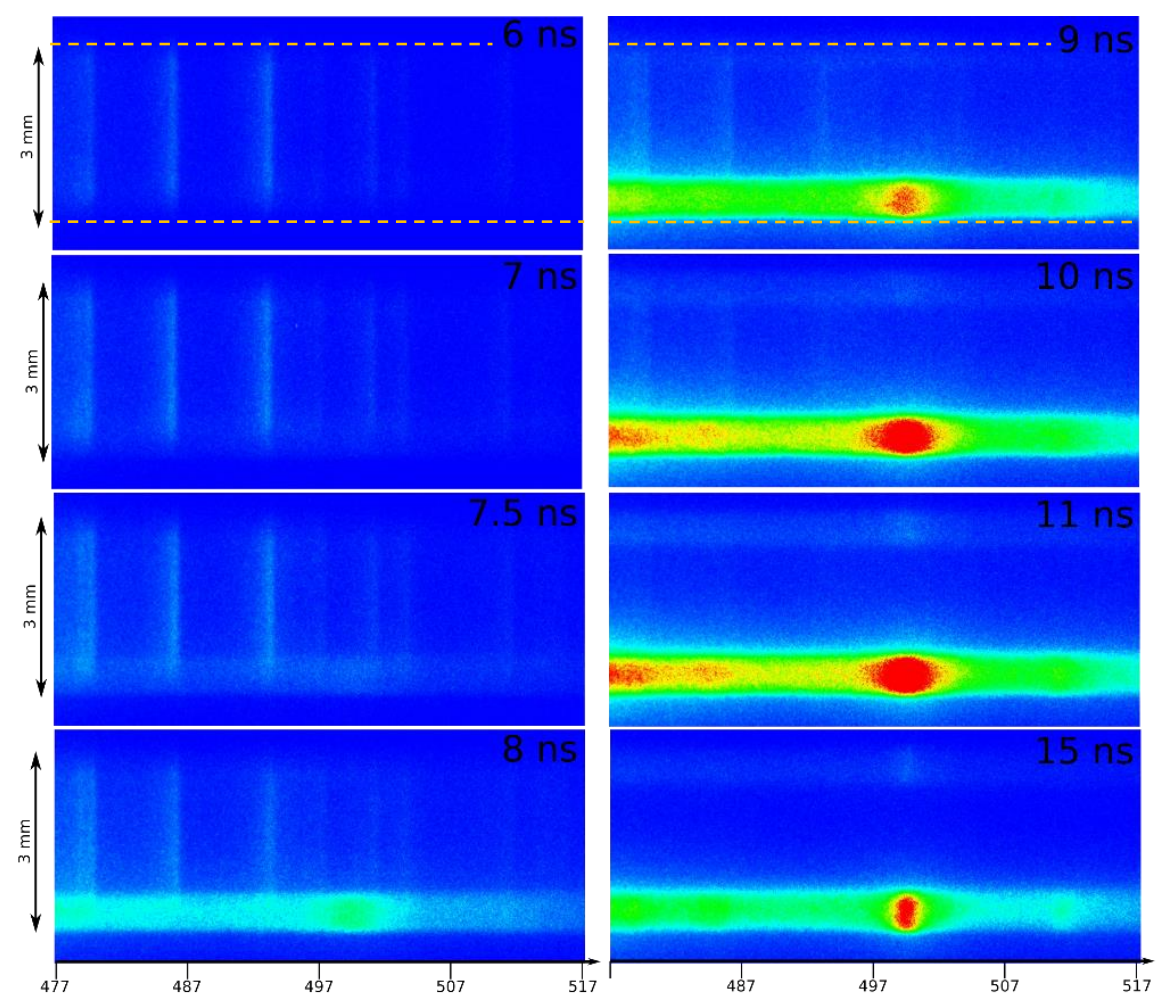

Fig. 6 Spatially resolved images of a nanosecond spark through a spectrometer using the 300 grooves/mm grating. The $x$ axis is the wavelength from 477 to $517 \mathrm{~nm}$ and the $y$-axis is real space aligned with electrodes (3 mm). Position of the electrode is showed on the left and emphasized by a yellow dashed line in the top images. The camera gate was $0.5 \mathrm{~ns}$ and exposure averaged on 1000 acquisitions. The time on top right corner of each image corresponds to the delay of the acquisition with first detectable emission. The typical electrical waveforms are showed in Fig. 2 . Before the transition at $t$ $=7.5 \mathrm{~ns}$, the emission is only due to the second positive system of nitrogen. After the transition, the spectra are dominated by a strong continuum and $\mathrm{N}^{+}$emission (strongest line at $500 \mathrm{~nm}$ ). The scale of intensity (blue to red) is the same for all 8 pictures.

\section{Conclusion}

We have investigated nanosecond discharges initiated in pin-to-pin geometry by high-voltage pulses in ambient air. Two regimes were distinguished: the non-equilibrium spark, named here "spark", and the equilibrium spark, named here "arc". The spark regime is characterized by molecular emission, gas temperature below $2000 \mathrm{~K}$ and maximum electron number density of $10^{15} \mathrm{~cm}^{-3}$. The arc regime is associated with ionic emission of atoms combined with a broadband continuum, gas temperature of $39,000 \mathrm{~K}$ (approximately $3 \mathrm{eV}$ ) and electron number density of $10^{19} \mathrm{~cm}^{-3}$ (full ionization). In our conditions (pulses of $10 \mathrm{~ns}$ ), the transition between the two regimes occurred at $\mathrm{t}=7.5 \pm 1 \mathrm{~ns}$, in a period shorter than $1 \mathrm{~ns}$. The transition starts near the cathode and propagates toward the middle of the interelectrode gap. Characteristic speed of propagation of the transition wave is $10 \mu \mathrm{m} / \mathrm{ns}$. 
In the future work the investigation of transition at various pressures and voltages will be conducted. The present observations demonstrate the morphology of the spark to arc transition of nanosecond discharges in ambient air.

\section{Bibliography}

[1] D. Z. Pai, D. A. Lacoste, and C. O. Laux, "Nanosecond repetitively pulsed discharges in air at atmospheric pressure-the spark regime," Plasma Sources Sci. Technol., vol. 19, no. 6, 2010.

[2] D. L. Rusterholtz, D. A. Lacoste, G. D. Stancu, D. Z. Pai, and C. O. Laux, "Ultrafast heating and oxygen dissociation in atmospheric pressure air by nanosecond repetitively pulsed discharges," $J$. Phys. D. Appl. Phys., vol. 46, no. 46, p. 464010, Nov. 2013.

[3] D. Z. Pai, D. A. Lacoste, and C. O. Laux, "Transitions between corona, glow, and spark regimes of nanosecond repetitively pulsed discharges in air at atmospheric pressure," J. Appl. Phys., vol. 107, 2010.

[4] D. Z. Pai, G. D. Stancu, D. A. Lacoste, and C. O. Laux, "Nanosecond repetitively pulsed discharges in air at atmospheric pressure - The glow regime,” Plasma Sources Sci. Technol., vol. 18, no. 4, 2009.

[5] S. V Pancheshnyi, D. A. Lacoste, A. Bourdon, and C. O. Laux, "Ignition of Propane-Air Mixtures by a Repetitively Pulsed Nanosecond Discharge," IEEE Trans. Plasma Sci., vol. 34, no. 6, pp. 2478-2487, Jun. 2006.

[6] Y. Ju and W. Sun, "Plasma assisted combustion: Dynamics and chemistry," Prog. Energy Combust. Sci., vol. 48, pp. 21-83, Dec. 2015.

[7] K. (Ken) Ostrikov, "Control of energy and matter at nanoscales: challenges and opportunities for plasma nanoscience in a sustainability age," J. Phys. D. Appl. Phys., vol. 44, no. 17, p. 174003, May 2011.

[8] D. Z. Pai, K. (Ken) Ostrikov, S. Kumar, D. A. Lacoste, I. Levchenko, and C. O. Laux, "Energy efficiency in nanoscale synthesis using nanosecond plasmas," Sci. Rep., vol. 3, no. 1, p. 1221, Dec. 2013.

[9] R. Dawson and J. Little, "Characterization of nanosecond pulse driven dielectric barrier discharge plasma actuators for aerodynamic flow control," J. Appl. Phys., vol. 113, no. 10, p. 103302, Mar. 2013.

[10] J. R. Roth, D. M. Sherman, and S. P. Wilkinson, "Electrohydrodynamic Flow Control with a GlowDischarge Surface Plasma," AIAA J., vol. 38, no. 7, pp. 1166-1172, Jul. 2000.

[11] D. V. Roupassov, A. A. Nikipelov, M. M. Nudnova, and A. Y. Starikovskii, "Flow Separation Control by Plasma Actuator with Nanosecond Pulsed-Periodic Discharge," AIAA J., vol. 47, no. 1, pp. 168185, Jan. 2009.

[12] A. Lo et al., "Streamer-to-spark transition initiated by a nanosecond overvoltage pulsed discharge in air," Plasma Sources Sci. Technol., vol. 26, no. 4, p. 45012, Jun. 2017.

[13] S. A. Shcherbanev, A. Yu Khomenko, S. A. Stepanyan, N. A. Popov, and S. M. Starikovskaia, "Optical emission spectrum of filamentary nanosecond surface dielectric barrier discharge," Plasma Sources Sci. Technol., vol. 26, no. 2, p. 02LT01, Mar. 2016.

[14] N. A. Popov, "Fast gas heating in a nitrogen-oxygen discharge plasma: I. Kinetic mechanism," $J$. Phys. D. Appl. Phys., vol. 44, no. 28, p. 285201, Jul. 2011.

[15] N. A. Popov, "Kinetic processes initiated by a nanosecond high-current discharge in hot air," Plasma Phys. Reports, vol. 37, no. 9, pp. 807-815, Sep. 2011. 
[16] D. Rusterholtz, "Nanosecond Repetitively Pulsed Discharges in Atmospheric Pressure Air," Ecole Centrale Paris, 2012.

[17] D. Z. Pai, "Nanosecond Repetitively Pulsed Plasmas in Preheated Air at Atmospheric Pressure," Ecole Centrale Paris, 2008.

[18] C. O. Laux, T. G. Spence, C. H. Kruger, and R. N. Zare, "Optical diagnostics of atmospheric pressure air plasmas," Plasma Sources Sci. Technol., vol. 12, pp. 125-138, 2003.

[19] N. Konjević et al., "Experimental Stark widths and shifts for spectral lines of neutral and ionized atoms (a critical review of selected data for the period 1989 through 2000)," J. Phys. Chem. Ref. Data, vol. 31, no. 3, pp. 819-927, Jun. 2002.

[20] H. R. Griem, Plasma spectroscopy. McGraw-Hill Book Company, 1964.

[21] F. Bastien and E. Marode, "The determination of basic quantities during glow-to-arc transition in a positive point-to-plane discharge," J. Phys. D. Appl. Phys., vol. 12, no. 2, pp. 249-263, Feb. 1979.

[22] "Specair 3.0." 2013.

[23] A. Kramida, J. Reader, Y. Ralchenko, and NIST ASD Team, "NIST ASD," NIST Atomic Spectra Database (ver. 5.6.1), 2018. [Online]. Available: https://physics.nist.gov/asd.

[24] M. A. Gigosos, M. Á. González, and V. Cardeñoso, "Computer simulated Balmer-alpha, -beta and gamma Stark line profiles for non-equilibrium plasmas diagnostics," Spectrochim. Acta - Part B At. Spectrosc., vol. 58, no. 8, pp. 1489-1504, Aug. 2003.

[25] N. Konjević, M. Ivković, and N. Sakan, "Hydrogen Balmer lines for low electron number density plasma diagnostics," Spectrochim. Acta Part B At. Spectrosc., vol. 76, pp. 16-26, Oct. 2012.

[26] M. Cernak, E. M. van Veldhuizen, I. Morva, and W. R. Rutgers, "Effect of cathode surface properties on glow-to-arc transition in a short positive corona gap in ambient air," J. Phys. D. Appl. Phys., vol. 28, no. 6, pp. 1126-1132, Jun. 1995.

[27] T. Shao et al., "Spark discharge formation in an inhomogeneous electric field under conditions of runaway electron generation," J. Appl. Phys., vol. 111, no. 2, 2012. 